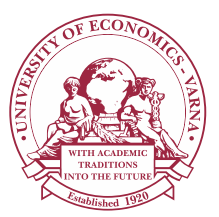

Izvestiya Journal of Varna University of Economics 2 (2021)

IZVEST IYA

Journal of Varna University of Economics

http://journal.ue-varna.bg

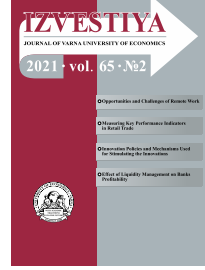

\title{
INNOVATION POLICIES AND MECHANISMS USED FOR STIMULATING THE INNOVATIONS IN THE FIVE LEADING AFRICAN COUNTRIES
}

\author{
Plamen PAVLOV ${ }^{1}$
}

${ }^{1}$ Department of Industrial Business and Logistics, University of Economics, Varna, Bulgaria, E-mail: pavlov@ue-varna.bg

JEL: 0380

\begin{abstract}
Innovations in the modern world are of great importance for everyone. They are the basis for high competitiveness of companies, economic growth of economies and prosperity of societies. The scientific objective of the article is to identify the various levers, models and specific incentives for innovation and research and development (R\&D) in the five leading African countries in this area, according to the Global Innovation Index 2020. On this basis, conclusions and guidelines have been worked out, that are useful both from a scientific point of view and for improving the renewed innovation policy of Bulgaria. The article uses various research methods and approaches, including methods of analysis and synthesis, comparison and causation, as well as systematic and complex approaches.
\end{abstract}

Key words:

innovation policies, innovations, stimulating innovation

(C) 2021 University of Economics - Varna

Citation: PAVLOV, Plamen. Innovation Policies and Mechanisms Used for Stimulating the Innovations in the Five Leading African Countries. Izvestiya Journal of Varna University of Economics, 65 (2), pp. $176-190$.

DOI: 10.36997/IJUEV2021.65.2.176

\section{Introduction}

In the modern world innovations are one of the most fundamental factors for the development, growth and improvement of the competitiveness of companies and economies, as well as for improving the quality of life in societies. They are implemented in the high-tech economic sectors, as well as in the traditional ones such as education, medicine and services. In which sectors of the economy and social life 
Plamen Pavlov. Innovation Policies and Mechanisms Used

for Stimulating the Innovations in the Five Leading African Countries

should innovation be supported and what specific mechanisms should be applied to stimulate it, is definitely a prerogative of the innovation policy of each country. And although when referring to innovation it is usually associated with the world's leading economies, we must keep in mind that, in fact, efforts are being made in all parts of the world to stimulate innovation. Of particular interest are countries that have limited financial resources and many political, economic and social problems and yet they find the right tools to pursue national innovation policies. Moreover, in many countries with weaker economies there has been achieved relatively high efficiency of the implemented measures. This is exactly the situation in several African countries, which are leaders among the others in the region. In line with this statement, the scientific objective of the article is to identify the various levers, models and specific incentives for innovation and research and development (R\&D) in the five leading African countries in this area, according to the Global Innovation Index 2020, and to draw conclusions and work out guidelines that are useful both from a scientific point of view and for improving the renewed innovation policy in Bulgaria. The article uses various research methods and approaches, including methods of analysis and synthesis, comparison and causation, as well as systematic and complex approaches.

\section{Nature of the innovation policies}

In our opinion it can be pointed out that innovation policy covers a wide variety of measures for economic regulation, taxation, depreciation policy, patent-licensing and antitrust legislation, regulation of the technology market, stimulating small and medium-sized innovative businesses and attracting funds for the implementation of innovations. But in addition to all these rather indirect measures, innovation policy can also use direct payments, low-interest or interest-free loans and subsidies ${ }^{2}$ for the development of innovative, high-tech or key country-specific businesses, as well as specific government contracts for the delivery of innovative products, services or processes. It is generally a course of action, a choice of objectives and guidelines, the adopted line, containing necessary activities and resources to achieve the targets and is related to the elements of management and governance. According to Borrás and Edquist (2013), innovation policy can be likewise defined as a combination of actions taken by public organizations that influence innovation processes. Furthermore, it is a set of strategies, programs, events and others aimed at creating favorable conditions for the accelerated development of R\&D and successful implementation of innovations in companies and the market (Raychev, 2014). In other words, innovation policy is the interface between research and technological development policy and industrial policy, and aims to create a favorable framework for bringing ideas to market (Gouardères, 
2020).

Properly developed and implemented innovation policy, according to Eremkin and Sutayrina (2012), should have a positive influence on the propensity for entrepreneurship, macro and microeconomic environment of interaction between companies and the education system, which on the one hand affects the attitude to innovation, and - on the other - creates competencies needed for innovation.

It is fundamental, in our opinion, to point out that innovation policy should cover not only the various types of industries, including both high-technology and traditional ones, but also all other areas of economic and social life, most precisely incentives for innovation in services, agriculture, social work, healthcare, etc.

One of the essential goals of innovation policy, in addition to satisfying various needs in society, is to increase the competitiveness of the economy. From this point of view, innovation policy could be a very powerful instrument in the hands of governments, because economic growth usually leads to an increase in people's welfare and also to an improvement in the quality of life - especially important for all African countries. In this regard, it is particularly important that each country's innovation policy focuses not only on certain tax breaks or direct subsides, but offers a wide range of opportunities, because for every company or individual innovator that is trying to make an innovation successful, there are various so-called "most appropriate" incentives to succeed. For some of them, the problems are in the initial stages and assistance should focus on the phases related to generating ideas or creating pilot series. For others, the difficulties are in the subsequent phases, such as the marketing of new products or services respectively, innovation policy should provide incentives in this field, etc.

One of the last references we could make in terms of innovation is the continent of Africa. Possibly because the economic development of most African countries is much lower than that of the world's leading economies, since most African countries have been independent for only a few decades, and since in most of them the essential difficulties do not stem from how to achieve the highest standard of living, but rather from how to overcome basic problems such as hunger or providing the population with medicines or basic necessities. However, there are several countries in Africa that pay special attention to innovation and pursue targeted policies to stimulate it. These include Mauritius, South Africa, Tunisia, Morocco and Kenya. They are ranked first in the ranking of the Global Innovation Index for 2020 (Fig.1). 


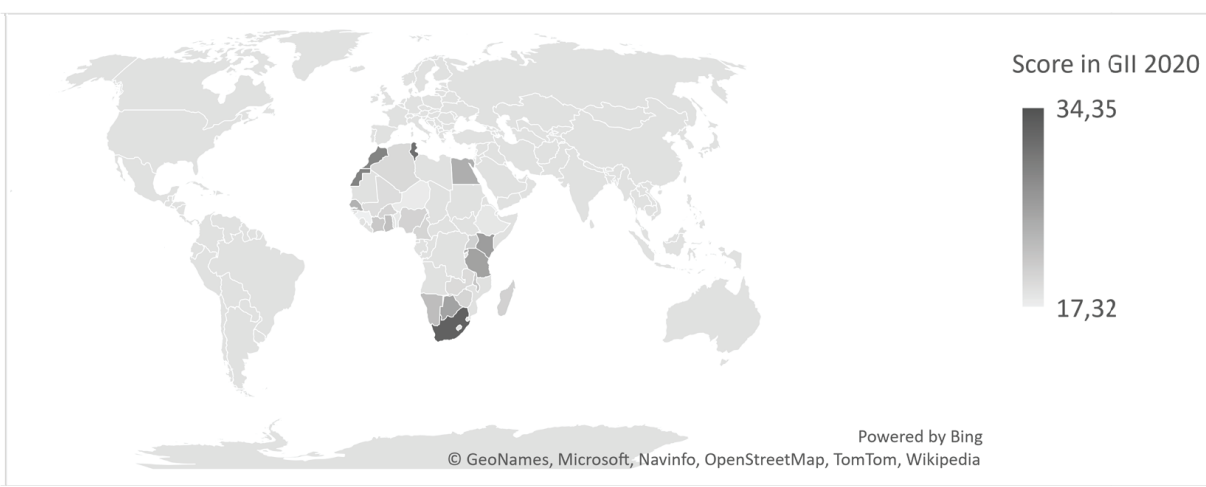

Fig. 1. The most innovative African countries according to GII 2020

Source: The author, based on information by WIPO, (2020)

As the funds that these countries allocate to stimulate innovation are not very large (except in South Africa), but apparently some of them are spent quite effectively, the examination of their innovation policies and various specific levers and mechanisms to stimulate innovation and $\mathrm{R} \& \mathrm{D}$ may be interesting and useful in developing a future improved innovation policy for Bulgaria.

In this regard it is necessary to consider the specific innovation policies in the top five countries according to GII 2020 in Africa - Mauritius, Republic of South Africa, Tunisia, Morocco and Kenya.

\section{Innovation policy of Mauritius}

Mauritius is the leading country in the area of innovation for the continent of Africa. According to GII 2020, it ranks 52nd in the world with an index of 34.35 (WIPO, 2020). An interesting fact about the country is that by 2018 it is usually above the 80th place in the GII rankings. Since 2019, however, the government in Mauritius has relied heavily on innovation, not only on paper, but also as a real implementation of measures aimed at improving innovation, and there is a leap by 30 places upward in the rankings of GII 2020.

The country's innovation policy is implemented with the leading role of the Government and in particular of the Ministry of Information Technology, Communication and Innovation (Ministry of Information Technology, Communication and Innovation, 2020). The Mauritius Research and Innovation Council also takes an active part in stimulating innovation. Since 2018, the country has adopted several important documents in the area of innovation, including the National Innovation 
Framework 2018-2030 (National Innovation Framework, 2018), Digital Mauritius 2030 (Digital Mauritius, 2030) and Mauritius Artificial Intelligence Strategy (2018). These are documents that outline the principles and the focus of the island's innovation policy until 2030.

In Mauritius there are various options for directly stimulating innovation and research, such as the Research and Innovation Grant Scheme - CRAIGS (MRIC, 2020), which grants innovative projects up to around $€ 100,000$. Other instruments are the Intellectual Property Promotion Scheme - IPPS, the Social Innovation Research Grant Scheme, the National SME Incubator Scheme (NSIS), Research and Innovation Bridges and others.

In addition, for the period 2014-2020, Mauritius, in cooperation with EU representatives, participated in two projects within the European Programme "Horizon 2020 " in the areas of "Leadership in enabling and industrial technologies" and "Marie Sklodowska Curie Actions" (European Commission, 2020). The island also participates in EU's Seventh Framework Programme, with six participants in six projects, half of them covering the scientific field of information and communication technologies.

In Mauritius, there are tax reliefs for innovation and $\mathrm{R} \& \mathrm{D}$, and in addition to the many tax rebates that can be used in the various economic sectors in the country, from 2017 onwards an exemption from income tax on innovative products applies for a period of eight years if they can be patented, or if it is software, it must be able to be protected as copyright (Lomas, 2017).

The total R\&D expenditure in Mauritius for $2016-2018$ is between $0.4 \%$ and $0.3 \%$ of GDP (UNESCO, 2020). In real terms, this is about 42.8 million euros per year. The total cost of $R \& D$ per capita is about 33 euros.

\section{Innovation policy of Republic of South Africa}

The Republic of South Africa, according to GII 2020, is ranked second among the countries of the continent. It ranks 60th in the world with an index of 32.67 (WIPO, 2020).

The most important document outlining the roadmap for South Africa's transition to a diversified economy by 2030 is the National Development Plan (South African Government, 2012). It applies to both the economic and social, and the cultural policy of the country, having innovation at the heart of almost every area.

Other important elements in the implementation of the country's innovation policy are the National Integrated Cyber Infrastructure System (SCIR, 2020) and the Industrial Policy Action Plan 2018/19 - 2020/21 (South African Government, 2018). The integrated system encourages scientific and industrial development by 
Plamen Pavlov. Innovation Policies and Mechanisms Used

for Stimulating the Innovations in the Five Leading African Countries

providing high-performance computing capabilities, high-speed network capacity and a national research data infrastructure, providing seamless access for the research and educational communities in South Africa. The Action Plan provides a framework for the development of the entire South African industry, with a special place for innovation and technology, including that of technological maturation and commercialization of large research and development projects, that have the potential to create significant industries in emerging technological spheres.

The principal bodies involved in the implementation of innovation policy in the Republic of South Africa are the Ministry of Higher Education, Science and Technology, the Ministry of Trade, Industry and Competition, the Ministry of Telecommunications and Postal Services, the Academy of Sciences of the South African Agency for Technological Innovation.

Direct funding of innovative activities in South Africa can be obtained through various programs (Technological Innovation Agency, 2020) such as: 1) The Technology Stations Program, whose goal is to improve the competitiveness of the industry by applying specialized knowledge, innovation and technology and facilitating the interaction between industry and academia. 2) The Innovation Program for Inclusive Development. 3) The Youth Technology Innovation Program. Its goal is financing and supporting young people aged 18 to 30 who have innovative ideas that have the potential to start a new business. 4) The Cleantech Global Innovation Program, whose goal is fostering innovation in clean technologies and helping entrepreneurs grow their small, medium, micro and start-up enterprises. 5) The Innovation Skills Program.

In South Africa, indirect stimulation of innovation through tax relief for companies is also used (Department of Science and Innovation, 2019). Up to $150 \%$ of current or capital R\&D costs can be deducted from taxable corporate income, without a ceiling on the amount. This incentive is available for businesses of all sizes (both SMEs and large ones) and in all sectors of the economy.

Total R\&D expenditure in the Republic of South Africa (UNESCO, 2020) for 2016-2018 is $0.8 \%$ of GDP. In real terms, this is between 1.6 and 1.9 billion euros a year.

\section{Innovation policy of Tunisia}

Tunisia is the third country according to GII 2020 for the continent of Africa. It ranks 65 th in the world with an index of 31.21 (WIPO, 2020).

In Tunisia, innovation policy is the responsibility of the Ministry of Industry and SMEs, through the Agency for the Promotion of Industry and Innovation. It implements government policy related to the promotion of the industrial sector and innovation. 
The Center itself also has a Center for Innovation and Technological Development (Center d'Innovation et de Développement Technologique, 2020). The Ministry of Higher Education and Research also participates in the implementation of the country's innovation policy. In addition, Tunisia has a National Agency for the Promotion of Research, whose key aim is to support public research structures. Technopolises, which represent places in which activities in the field of education, scientific and technical research, production and technological development are located, also play an important role in terms of innovation in the country. Their main goal is to promote the competitive capacity of the economy and to develop its technological components by stimulating technological innovation.

In the area of innovation and high technology, the National Strategic Plan Digital Tunisia 2020 is in effect in the country, and since the beginning of 2020 a National Strategy for the Promotion of Industry and Innovation 2035 is being prepared.

In Tunisia, several programs and various funds that stimulate innovation are being implemented, such as the Upgrade Program (PMN) and the Business Competitiveness and Market Access Facilitation Program (PCAM); the Risk Mutual Fund (IN'TECH), which finances high-tech innovative projects; the Industrial Decentralization Promotion Fund (FOPRODI); The incentive scheme for creativity and innovation in the field of information and communication technologies (RIICTIC); The Start-up Innovation Fund invests in equity shares of start-up innovative companies that have strong development potential, and then, when the innovative companies establish themselves on the market, it has the opportunity to repurchase their shares.

In Tunisia, there are also some tax breaks for innovation (Agence de Promotion de 1'Industrie et de l'Innovation, 2020), such as: sector, but excluding renewables, mining, real estate, local consumption, trade and telecommunications). Tax exemption for the first four years for start-ups, including innovative ones, as follows: $100 \%$ for the first year, $75 \%$ for the second year, $50 \%$ for the third year, $25 \%$ for the fourth year.

Gross domestic R\&D expenditure in Tunisia (UNESCO, 2020) for the period 2016-2018 is $0.6 \%$ of GDP or in monetary terms between 185 and 216 million euros per year.

\section{Innovation policy of Morocco}

Morocco is the fourth country according to GII 2020 for the continent of Africa. It ranks 75th in the world with an index of 28.97 (WIPO, 2020). However, in the country there are developed and are implemented several strategic documents in the area of innovation and research (Royaume du Maroc, 2020), the most important of which are the Morocco Innovation Strategy and the National Strategy for the development 
Plamen Pavlov. Innovation Policies and Mechanisms Used

for Stimulating the Innovations in the Five Leading African Countries

of scientific research until 2025 (Royaume du Maroc, Ministère de 1'Enseignement Supérieur, de la Recherche Scientifique et de la Formation des Cadres, 2020).

The main institutions and organizations, responsible for implementing innovation policies in Morocco, are the Standing Ministerial Committee for Research and Technological Development, the Ministry of Higher Education, Research and Training, the Hassan II Academy of Sciences and Technology, the Supreme Council for education, teaching and research, the National Fund for the Support of Research and Technological Development, the National Center for Scientific and Technical Research.

In the North African country various programs for direct stimulation of innovation and $R \& D$ have been implemented at the national level in recent years. Such are the Morocco Incubation and Development Network; the INOV'ACT program; Programs to promote excellence; University and business partnership programs. In addition, innovators and scientists from Morocco have the opportunity to receive funding for international programs such as the Moroccan-Walloon Cooperation, Moroccan-Qatari Cooperation as well as other bilateral programs.

In Morocco, there are no tax breaks especially and only for innovation or R\&D. But innovators can take advantage of discounts in areas such as the automotive, aerospace, electronics, chemical, and pharmaceutical industries through the Hassan II Fund (Moroccan Investment Development Agency, 2020). In addition, for large investment projects - over 9.2 million euros, including innovative ones - exemption from VAT and import duties may be requested. In the field of agriculture, tax relief can also be used (Worldwide Tax Summaries Online, 2020), including relief for innovative companies, with discounts varying depending on the size of the company.

Gross domestic R\&D expenditure in Morocco (UNESCO, 2020) according to the latest available data (for 2010) is $0.7 \%$ of GDP or in monetary terms it is about 510 million euros.

\section{Innovation policy of Kenya}

Kenya is the fifth country according to GII 2020 for the continent of Africa. It ranks 86th in the world with an index of 26.13 (WIPO, 2020).

The main institutions and organizations responsible for implementing Kenya's innovation policy are the Ministry of Science, Technology and Innovation, the National Commission for Science, Technology and Innovation (NACOSTI, 2020), the Kenyan National Innovation Agency and the National Research Fund.

The Ministry of Science, Technology and Innovation is responsible for the policy, planning and control over the financing of innovation and R\&D. It coordinates the implementation of flagship programs for all line ministries, departments and agencies 
with respect to science, technology and innovation.

One of the important documents regarding the economic and social development of the country is Kenya Vision 2030. In it, along with a number of issues to be solved in areas such as income, health, nutrition, the essential role of science, technology and innovation are creating wealth and building the human capital needed to make the transition to a knowledge-based economy (Kenya Vision 2030, 2017). In addition, the Ministry of Education in Kenya has developed a Science, Technology and Innovation Policy (Republic of Kenya, Ministry of Education, 2017), which contains in-depth analysis, vision, targets, policies and strategies in these areas. Especially in the field of innovation, efforts are envisaged, which include the development of innovation centers, business incubators, science parks and special economic zones to convert ideas, research or prototypes of viable products and services.

In Kenya, there are several programs for funding innovation and R\&D that can receive direct funding, such as the Science, Technology and Innovation Grant; the ICT capacity building; the Fostering ICT entrepreneurship; the National Innovation Awards; the Scholarships for innovation leaders and others.

Indirect incentives focus on tax breaks that are not directly meant for innovation and $R \& D$, but can benefit all companies that have invested in Kenya (Kenya Revenue Authority, 2020). Discounts are most often in the form of increased depreciation rates for the first year (in some cases for subsequent years) after investing in buildings, machinery, farming or for the purchase or acquisition of the right to use an optical cable from a telecommunications operator, and vary between $10 \%$ and $50 \%$.

According to the latest available data (for 2010), the gross domestic expenditure on R\&D in Kenya (UNESCO, 2020) is $0.8 \%$ of GDP or in monetary terms it is about 380 million euros.

\section{Analysis of the characteristics of innovation policies in the five African countries}

If we analyze these five leading innovation countries in Africa in more detail, we will find that there are a number of similarities. All of them have developed strategic documents in the area of innovation policy. And although their focus is different - from innovation in industry, agriculture, research and development, to high innovation of SMEs or something else, policies are implemented by trying to implement different, but as appropriate as possible country-specific approaches and incentives.

In all five countries considered, the main drivers for the implementation of innovation policy are governments - directly through certain ministries or through specific government agencies. 
Plamen Pavlov. Innovation Policies and Mechanisms Used

for Stimulating the Innovations in the Five Leading African Countries

Another important feature in these African countries is the presence of indirect incentives for innovation or R\&D in each of them. Of course, there are nuances - in Mauritius, the Republic of South Africa and Tunisia, the relief is tax-related and is directly aimed at R\&D and innovation. There are also tax breaks in Morocco and Kenya, but they target all eligible investments, including those for innovation activities; however they are not specifically prepared for innovation and R\&D. Considering all the observations made thus far, we may need to conclude that tax incentives that are directly aimed at stimulating innovation and $R \& D$ are more effective than general measures in this direction, because Mauritius, South Africa and Tunisia are in the GII 2020 ranking far ahead of Morocco and Kenya who do not offer such special relief.

Another fact is that in all five countries, gross domestic expenditure on R\&D as a percentage of GDP is between $0.3 \%$ in Mauritius and $0.8 \%$ in South Africa and Kenya (Figure 2), which is a very low level compared to the leading innovative countries in the world, (for example in Israel and the Republic of Korea - these costs are over 4.5\%) (UNESCO, 2020). Moreover, these are the top five countries on the African continent in terms of innovation.

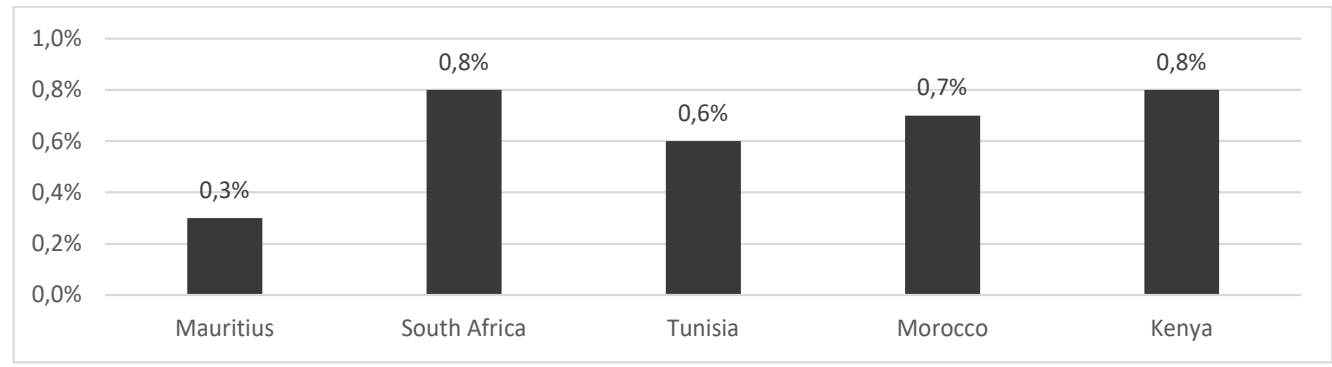

Fig. 2. Gross domestic R\&D expenditure in Mauritius, South Africa, Tunisia, Morocco and Kenya

Source: The author, based on information by UNESCO, (2020)

On the other hand - the low costs that Mauritius incurs, but the good results achieved - show that the chosen main tools and levers in the innovation policy of the country are used correctly and give good results. This means that it is essential, in order to achieve high innovation in different economies, to not only spend a lot of money, but make sure they are properly targeted and implemented through the most appropriate instruments of innovation policy in a particular country.

Other important information on the innovation policies of the five leading African countries according to GII 2020 and the funds they spend on stimulating innovation 
and research can be obtained by looking at the GDP per capita R\&D expenditures. This indicator can be determined by relating $R \& D$ expenditure to $R \& D$ to the population of the country concerned (Table 1 ).

Table 1

Expenditure of GDP on R\&D, distributed per capita

\begin{tabular}{|l|c|c|c|c|}
\hline \multicolumn{1}{|c|}{ Country } & $\begin{array}{c}\text { Place in } \\
\text { GII 2020 }\end{array}$ & $\begin{array}{c}\text { GDP expenditure } \\
\text { on R\&D in millions } \\
\text { of Euros }\end{array}$ & Population & $\begin{array}{c}\text { Expenditure of GDP } \\
\text { on R\&D per capita } \\
\text { in Euro }\end{array}$ \\
\hline I & II & III & IV & V=III/IV \\
\hline 2. Republic of South Africa & 62 & 42.8 & $1,295,462$ & 33.04 \\
\hline 3. Tunisia & 65 & 1,900 & $57,092,143$ & 33.28 \\
\hline 4. Morocco & 75 & 216 & $11,805,501$ & 18.30 \\
\hline 5. Kenya & 86 & 510 & $36,439,551$ & 14.00 \\
\hline
\end{tabular}

Source: Data on GDP expenditure on R\&D are from UNESCO (2020). Data on the population of the countries are from Wikipedia (2020).

Based on these data, it can be assumed that in all five countries, the GDP expenditure on R\&D per capita is not high - about 33 euros in Mauritius and South Africa - and extremely modest - 7.4 euros - in Kenya. This, together with the low percentage of gross domestic $\mathrm{R} \& \mathrm{D}$ spending, are in fact two of the important reasons why even the leading countries on the continent of Africa are outside the top fifty in the world in terms of innovation.

From the analyses and conclusions made, three important guidelines can be drawn regarding the development of a new innovation policy in Bulgaria. First, although the measures applied to stimulate innovation are extremely diverse, they must be selected in such a way as to best suit the specific characteristics of the economy and society. Here, too, it must be emphasized that a package of long-term, well-considered measures is needed, not current short-term solutions. Second, the availability of specific tax rebates for innovative companies or individual innovators has a positive effect on the whole economy and is an important factor in improving the innovation of the country that implements them. In the case of Bulgaria - the low corporate tax for all economic entities is clearly not a sufficient incentive in this direction and it is necessary to think in the direction of reducing the tax and perhaps the insurance burden for highly-qualified staff (Bulgarian and foreign), engaged in research and other innovative activities, both 
Plamen Pavlov. Innovation Policies and Mechanisms Used

for Stimulating the Innovations in the Five Leading African Countries

in scientific organizations and in enterprises of the various economic sectors. Third, the achievement of significant results in the field of innovation and R\&D is linked to the direct costs of GDP in this direction. Unfortunately, in this aspect Bulgaria, with a cost of about 60 euros per capita is very far from the world's innovation leaders: Switzerland - over 2,380 euros, Israel - over 1,890 euros and Sweden - 1,530 euros (UNESCO, 2020) and much nearer the leading African countries Mauritius and South Africa. This actually means that in the majority of cases in our country, innovations happen despite the intervention on the part of the state, and not with its help. It is of great importance that the expenditures on $R \& D$ and innovation be proposed as a priority item in the following republican budgets in order to achieve more significant results.

\section{Conclusion}

Although globally the five African countries under study are not among the leaders in innovation, in regional terms they are leaders in this field. When analyzing the innovation capacity of different countries, there must be taken into account a number of other details, related to their overall economic development, recent political and social issues (as in South Africa, Morocco, Tunisia), entrepreneurial attitudes and many other factors, which affect innovation. However, these countries have a few things in common besides being leaders in innovation in Africa. All of them implement various programs for direct financing of innovation and R\&D in their countries, which are funded from the national budgets and elsewhere, the specific ministries or other government bodies or agencies implement national innovation policies. It is important to note that in all of these 5 countries, in an effort to develop innovation, tax relief is used - directly aimed at both $\mathrm{R} \& \mathrm{D}$ and innovation and common to various investment projects, as indirect measures in this respect.

In conclusion, it must be stated that in order for an economy to be strong and innovative, it does not have to be rich in oil, or be a former colonial power, or one of the world's largest economies - prerequisites that can undoubtedly take precedence in that case. However, it is very important for the country to have the right policy and strategy for innovative development of the national economy, to use the appropriate fiscal incentives and for innovation to be a priority for the whole society.

\section{End notes:}

${ }^{1}$ Global innovation index provides detailed indicators for innovation in 131 countries and economies around the world (for 2020). It is an annual ranking of 
countries by their capacity and success in the area of innovation. It is published by Cornell University, INSEAD and the World Intellectual Property Organization in partnership with other organizations and institutions and it is based on both subjective and objective data obtained from several sources, including the International Telecommunication Union, the World Bank and the World Economic Forum. It's 81 indicators explore a broad vision of innovation, including the political environment, education, infrastructure and business complexity.

${ }^{2}$ However, here we must consider the fact that not all countries have complete freedom with regard to direct subsides, including those for innovation. (For example, EU member states)

\section{References:}

1. Agence de Promotion de l'Industrie et de 1'Innovation. (2020). Centre d'innovation et de développement technologique. Available at: http://www. tunisieindustrie.nat.tn/fr/doc.asp?mcat=22\&mrub=177 [Accessed: 14.12.2020]

2. Agence de Promotion de l'Industrie et de 1'Innovation, Available at: http:// www.tunisieindustrie.nat.tn/fr/doc.asp? mcat=12\&mrub=212 [Accessed: 14.12.2020]

3. Borrás, S., C. Edquist. (2013). The choice of innovation policy instruments, Technological Forecasting \& Social Change, 80, p.1513;

4. Eremkin, V, T. Sutayrina. (2012). Instrumentay innovatsionnoy politiki: teoriya i praktika, Moskva, s. 6

5. European Commission. (2020). EU - Mauritius cooperation in Research \& Innovation, Available at: https://ec.europa.eu/research/iscp/pdf/policy/mauritius h2020_factsheet_press_pack.pdf [Accessed: 06.11.2020]

6. Gouardères, F. (2020). Innovation policy. Apr.2020. Available at: https:// www.europarl.europa.eu/factsheets/en/sheet/67/innovation-policy , [Accessed: 15.07.2020]

7. Kenya Revenue Authority. (2020). Taxation for Companies \& Partnerships. Available at: https://www.kra.go.ke/en/business/companies-partnerships/ companies-partnerships-pin-taxes/companies-partnerships-incentives-exemptions [Accessed: 16.12.2020]

8. Kenya Vision 2030. (2017). Science Technology and Innovation 20132017. Available at: https://vision2030.go.ke/publication/science-technology-andinnovation-2013-2017/ [Accessed: 16.12.2020]

9. Lomas, U. (2017). Tax Incentives Announced In Mauritius Budget, Wolters Kluwer, Available at: https://www.tax-news.com/news/Tax_Incentives_Announced_ In_Mauritius_Budget 74472.html [Accessed: 06.11.2020] 
Plamen Pavlov. Innovation Policies and Mechanisms Used

for Stimulating the Innovations in the Five Leading African Countries

10. Moroccan Investment Development Agency. (2020). Investment Incentives Available at: http://www.invest.gov.ma/?lang=en\&Id=20 [Accessed: 14.12.2020]

11. NACOSTI - National Commission for Science, Technology and Innovation. (2020). Available at: https://www.nacosti.go.ke/ [Accessed: 16.12.2020]

12. Raychev, T. (2014). Inovatsii v stroitelstvoto, Nauka i ikonomika, IU-Varna, p. 242.

13. Republic of Kenya, Ministry of Education. (2017). Science, Technology and Innovation Policy. Available at: https://www.nacosti.go.ke/images/docs/2018/ november/news/DRAFT\%20ST\&I\%20POLICY.pdf [Accessed: 16.12.2020]

14. Republic of Mauritius, Ministry of Information Technology, Communication and Innovation, (2020), Available at: https://mitci.govmu.org/SitePages/Index. aspx\#en [Accessed: 06.11.2020]

15. Republic of Mauritius, Ministry of Information Technology, Communication and Innovation, National Innovation Framework 2018 - 2030, oct.2018, Available at: http://www.mric.mu/English/Documents/Booklet_NIF.pdf [Accessed: 06.11.2020]

16. Republic of Mauritius, Ministry of Information Technology, Communication and Innovation, Digital Mauritius 2030, Available at: https://mitci.govmu.org/ Documents/Strategies/DM\%202030\%2017\%20December\%202018\%20at\%20 12.30hrs.pdf [Accessed: 06.11.2020]

17. Republic of Mauritius, Ministry of Information Technology, Communication and Innovation, Mauritius Artificial Intelligence Strategy, nov.2018, Available at: https://mitci.govmu.org/Documents/Strategies/Mauritius\%20AI\%20Strategy.pdf [Accessed: 06.11.2020]

18. Republic of Mauritius, Ministry of Information Technology, Communication and Innovation, (2020), Collaborative Research and Innovation Grant Scheme, Available at: http://www.mric.mu/English/Research\%20and\%20Innovation\%20 Schemes/Innovation $\% 20$ and $\% 20$ Commercialisation $\% 20 \mathrm{Schemes} / \mathrm{Pages} /$ Collaborative-Research-and-Innovation-Grant-Scheme-(CRIGS)-.aspx [Accessed: 06.11.2020]

19. République Tunisienne. (2020). Ministère des technologies de la communication. Plan National Stratégique Tunisie Digitale 2020, Available at: https://www.mtc.gov.tn/index.php?id=14 [Accessed: 14.12.2020]

20. Royaume du Maroc. (2020). Available at: https://www.enssup.gov.ma/fr/ Page/168-orientations-et-strat\%C3\%A9gies.html [Accessed: 14.12.2020]

21. Royaume du Maroc, Ministère de l'Enseignement Supérieur, de la Recherche Scientifique et de la Formation des Cadres. (2020). Stratégie nationale pour le développement de la recherche scientifique à l'horizon 2025. Available at: https://www. enssup.gov.ma/sites/default/files/PAGES/168/Strategie_nationale_recherche2025.pdf 
[Accessed: 14.12.2020]

22. RSA - Department of Science and Innovation. (2019). Available at: https:// www.dst.gov.za/rdtax/index.php/about-us [Accessed: 27.08.2020]

23. South African Government. (2012). National Development Plan 2030, Available at: http://www.gov.za/node/537988\#ndp2030 [Accessed: 27.08.2020]

24. South African Government. (2018). Industrial Policy Action Plan 2018/19 2020/21. Available at: https://www.gov.za/sites/default/files/gcis_document/201805/ industrial-policy-action-plan.pdf [Accessed: 27.08.2020]

25. Technological Innovation Agency. (2020). Available at: http://www.tia.org. za/ [Accessed: 27.08.2020]

26. The Council for Scientific and Industrial Research (SCIR). (2020). The National Integrated Cyber Infrastructure System. Available at: https://www.csir. co.za/national-integrated-cyber-infrastructure-system [Accessed: 27.08.2020]

27. UNESCO. (2020). Data for the Sustainable Development Goals. Available at: http://uis.unesco.org/en [Accessed: 06.11.2020]

28. Wikipedia, (2020), List of countries by population. Available at: https:// bg.wikipedia.org/wiki/\%D0\%A1\%D0\%BF\%D0\%B8\%D1\%81\%D1\%8A\%D0\%BA $\% \mathrm{D} 0 \% \mathrm{BD} \% \mathrm{D} 0 \% \mathrm{~B} 0 \% \mathrm{D} 1 \% 81 \% \mathrm{D} 1 \% 82 \% \mathrm{D} 1 \% 80 \% \mathrm{D} 0 \% \mathrm{~B} 0 \% \mathrm{D} 0 \% \mathrm{BD} \% \mathrm{D} 0 \% \mathrm{~B} 8$ \%D1\%82\%D0\%B5_\%D0\%BF\%D0\%BE_\%D0\%BD\%D0\%B0\%D1\%81\%D0\%B5 $\% \mathrm{D} 0 \% \mathrm{BB} \% \mathrm{D} 0 \% \mathrm{~B} 5 \% \mathrm{D} 0 \% \mathrm{BD} \% \mathrm{D} 0 \% \mathrm{~B} 8 \% \mathrm{D} 0 \% \mathrm{~B} 5$ [Accessed: 14.12.2020]

29. WIPO, (2020), Global innovation index 2020, Available at: https://www. wipo.int/global_innovation_index/en/2020/_Accessed: 05.11.2020]

30. Worldwide Tax Summaries Online. (2020). Available at: https://taxsummaries. pwc.com/morocco/corporate/tax-credits-and-incentives [Accessed: 16.12.2020] 